Eur J Appl Physiol 45, 19-24 (1980)

\title{
A Simple Method for Measuring Oxygen Uptake on a Single Breath Basis
}

\author{
Arsenio Veicsteinas ${ }^{1,3,4}$ and Maristella Gussoni ${ }^{2,3}$ \\ ${ }^{1}$ Department of Physiology III, University of Milan, via Mangiagalli 32, I-20133 Milan, Italy \\ ${ }^{2}$ Department of Physiology, University of Brescia, I-25100 Brescia, Italy; \\ ${ }^{3}$ Centro Studi di Fisiologia del Lavoro Muscolare del C.N.R., I-20133 Milan, Italy
}

\begin{abstract}
Summary. A simple method for calculating breath by breath $\mathrm{O}_{2}$ uptake by the conventional open circuit method is described. Each expiratory volume is collected in a collapsible bag (4 1 capacity) surrounded by a rigid box connected to a spirometer. A system of tubes with two solenoid valves operated by a manual switch allows the collection of air into the bag, during expiration, and its emptying by a vacuum pump during inspiration, respectively. The sampling line of a fast responding $\mathrm{O}_{2}$ and $\mathrm{CO}_{2}$ analyzer, together with temperature and pressure probes are inserted into the tube connecting the bag to the vacuum. The expired volume is therefore recorded (by the spirometer output) during expiration and its composition analyzed during the immediately following inspiratory phase, thus allowing gas exchange measurements to be performed on each single breath. $\dot{V O}_{2}$ measured by this method at steady state over periods of about 1 min yields substantially the same values as obtained by standard open circuit method (average ratio $=1.01$ ). Ventilations up to $150 \mathrm{l} / \mathrm{min}$ (ATPS) and respiratory rates up to $60 / \mathrm{min}$ can be easily followed. The simplicity of $\mathrm{VO}_{2}$ calculation, and the very limited dead space of the system (about $70 \mathrm{ml}$, downstream the expiratory valve), make this method particularly suitable for determining $\dot{V} \mathrm{O}_{2}$ kinetics at the onset and offset of exercise.
\end{abstract}

Key words: Oxygen uptake - Single breath - Kinetics of oxygen consumption - Metabolic transients - On- and off-responses

The half-time of the $\mathrm{O}_{2}$ consumption $\left(\mathrm{V}_{2}\right)$ adaptations at the onset and end of muscular exercise in man is of the order of $30 \mathrm{~s}$ (Diamond et al. 1977; Casaburi et al. 1977, 1978; Cerretelli et al. 1966, 1977, 1979; di Prampero et al. 1970; Hagberg et al. 1978; Henry 1951; Linnarson 1974; Margaria et al. 1965; Whipp et al. 1972). Thus, a good time resolution for assessing the kinetics of the $\mathrm{VO}_{2}$ on -

4 Present address: Department of Physiology, S.U.N.Y. at Buffalo, 120 Sherman Hall, Buffalo, NY 14214, USA

Offprint requests to: A. Veicsteinas, M.D. (address see above) 
and off - responses can be achieved only if $\dot{V} \mathrm{O}_{2}$ is determined on a single breath basis $\left(\dot{V}_{2}\right.$ s.b. $)$. This approach, however, requires tedious and time-consuming calculations, such as the volume integral, on each breath, of $\left(\mathrm{F}^{\prime} \mathrm{IO}_{2}-\mathrm{F}^{*} \mathrm{EO}_{2}\right) \mathrm{dV}$, where $\mathrm{F}^{\prime} \mathrm{IO}_{2}$ is the inspiratory $\mathrm{F}_{\mathrm{O}_{2}}$, corrected for respiratory quotient, and $\mathrm{F}^{*} \mathrm{EO}_{2}$ is the $\mathrm{F}_{\mathrm{O}_{2}}$ of the appropriate expired volume $(\mathrm{dV})$.

Similar calculations have been made by hand (di Prampero et al. 1970) and more recently by computer (Beaver et al. 1973; Cerretelli et al. 1977; Hagberg et al. 1978; Linnarson et al. 1974; Morabito et al. 1976; Whipp et al. 1972), or all together avoided by the use of mixing chambers (di Prampero et al. 1973), which introduce, however, time delays and profile distortions which are difficult to assess.

Alternatively, each expired air volume can be collected into a linear dry spirometer, the fast emptying of which (during the following inspiration) coupled with expired air analysis by means of rapid $\mathrm{O}_{2}$ and $\mathrm{CO}_{2}$ analyzers (response time $<100 \mathrm{~ms}$ ), allows measurement of $\mathrm{VO}_{2}$ on the single breath by conventional methods.

This relatively simple procedure yields a good approximation of single breath $\dot{V} \mathrm{O}_{2}$ (Cerretelli et al. 1977, 1979).

Nevertheless, the commercially available dry spirometers, when completely empty, have dead volumes of more than $600 \mathrm{ml}$ (cf. factory specifications of the Ohio Spirometer Mod. 822). This can affect the measurement of $\dot{V O}_{2}$ s.b., particularly at the beginning of the exercise and during recovery when the tidal volume is of the same order as the spirometer dead space and the variations of $\mathrm{P}_{\mathrm{O}_{2}}$ and $\mathrm{P}_{\mathrm{CO}_{2}}$ from one breath to another are relatively large (Wessel et al. 1979).

The present paper describes a simple method for measuring $\dot{V O}_{2}$ s.b. reducing calculations and dead space problems to a minimum.

\section{Material, Methods, and Experimental Procedure}

The basic equation for the measurement of $\mathrm{VO}_{2}$ by open circuit method is the following:

$$
\dot{V} \mathrm{O}_{2}=\frac{\left(\mathrm{F}_{\mathrm{IO}_{2}}^{\prime}-\mathrm{F}_{\mathrm{EO}_{2}}\right) \cdot \mathrm{V}_{\mathrm{T}}}{\mathrm{t}}
$$

where: $\mathrm{F}^{\prime} \mathrm{IO}_{2}$ is inspired oxygen fraction corrected for respiratory quotient, $\mathrm{F}_{\mathrm{EO} 2}$ is mixed expired $\mathrm{O}_{2}$ fraction of the expired tidal volume $V_{T}$, expressed at STPD, and $t$ is the time of the breath.

To obtain all the parameters required to solve Eq. (1) on a single breath, a 41 rubber anaesthesia bag is introduced into a rigid, air-tight transparent plastic box of about $10 \mathrm{l}$, connected in turn to a wedge or any other low resistance spirometer (Fig. 1). One branch (1 in Fig. 1) of a T tube $(3 \mathrm{~cm}$ internal bore) allows expired air to be collected in the rubber bag. The volume changes of the bag are monitored by the spirometer. The second branch of the T tube (2 in Fig. 1) is connected, via a $5 \mathrm{~cm}$ internal diameter tube, to a vacuum pump. The sampling line of $\mathrm{CCO}_{2}$ and $\mathrm{O}_{2}$ fast analyzer (a Varian MAT M50 mass spectrometer in our case) is inserted into this tube about $30 \mathrm{~cm}$ downstream from its origin, together with (a) the tip of a fast responding high sensitivity thermistor, to monitor expired air temperature and (b) a manometer to monitor the pressure in the evacuation tube. The third branch of the $\mathrm{T}$ tube ( 3 in Fig. 1 ) is connected to the expiratory side of a low resistance respiratory valve.

Two solenoid valves $(3.0 \mathrm{~cm}$ internal bore) are also placed in the system: one (a) immediately downstream from the expiratory valve (Fig. 1), the other (b) on the tube connected to the vacuum 


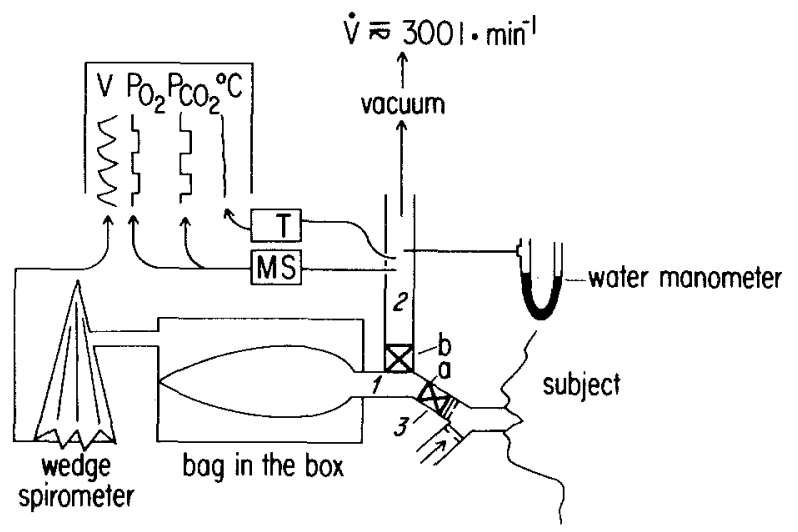

Fig. 1. Schematic drawing of the experimental set-up. a, b: solenoid valves; T: temperature recording; MS: mass spectrometer (see text for details)

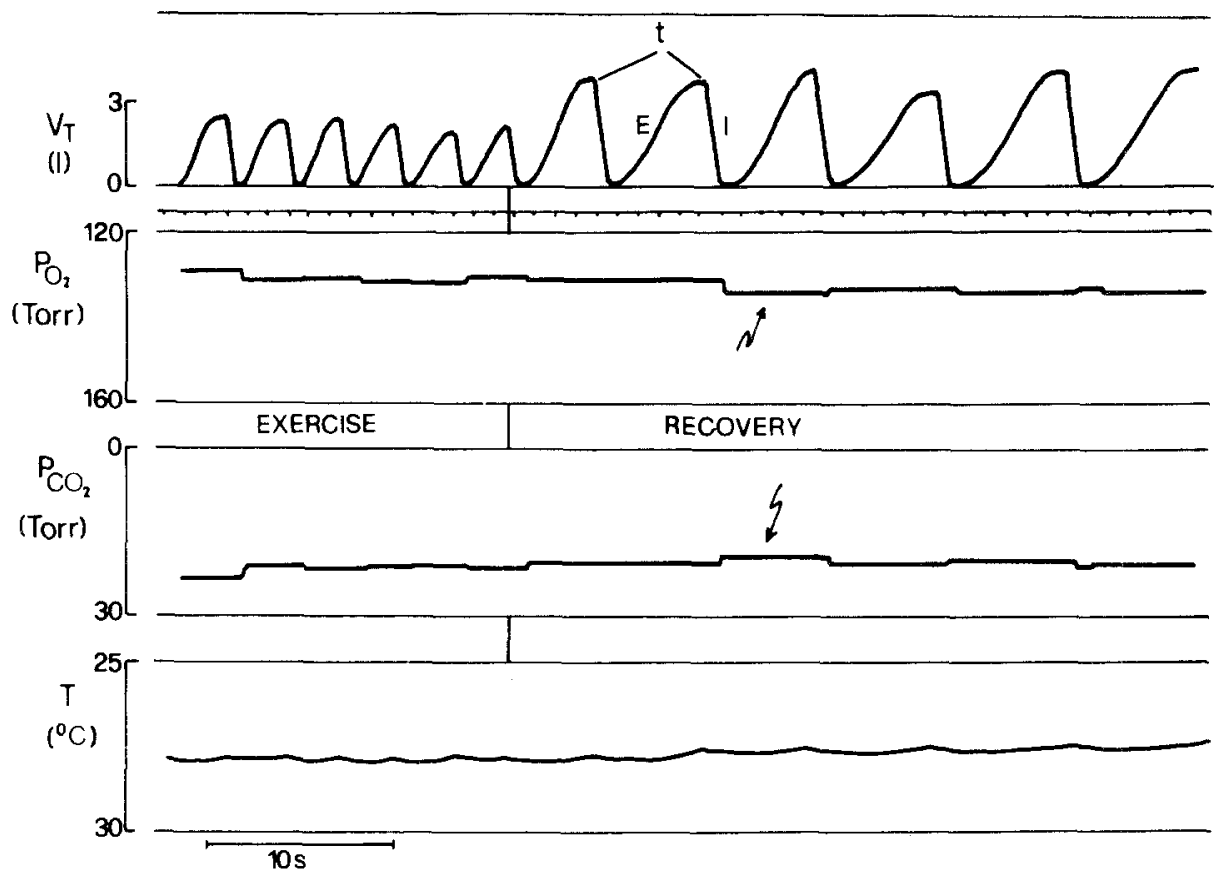

Fig. 2. Tidal volume, $\mathrm{V}_{\mathrm{T}}$, mixed expired $\mathrm{P}_{\mathrm{O}_{2}}$ and $\mathrm{P}_{\mathrm{CO}_{2}}$, and temperature changes are indicated in the transition from exercise to recovery from an actual tracing. Steady state $\mathrm{VO}_{2}=1.7 \mathrm{l} / \mathrm{min}$; steady state $\dot{V}_{\mathrm{E}}=50 \mathrm{l} / \mathrm{min}$. Duration of respiratory cycle, $t$, expiratory profile, $\mathrm{E}$, and the corresponding $\mathrm{P}_{\mathrm{O} 2}$ and $\mathrm{P}_{\mathrm{CO} 2}$ values (arrows) are indicated for a given breath, together with the following emptying of the rubber bag (I) at the sampling level

pump, upstream to the gas sampling line. The solenoid valves are wired in such a way that, when (a) is open, (b) is closed, and vice versa. The system is operated by a manual electric switch. Therefore, the bag can either be filled with expired air (during expiration) or quickly emptied by the vacuum pump (maximal flow $\simeq 300 \mathrm{l} / \mathrm{min}$ ) during inspiration. The dead space from the expiratory valve to the collapsible bag is $\simeq 70 \mathrm{ml}$. The $\mathrm{O}_{2}$ and $\mathrm{CO}_{2}$ partial pressures, together with the volume changes and the expired air temperature are continuously recorded (Fig. 2). 
The system is operated as follows. At the end of expiration, the electric switch is depressed: valve (a) is closed, valve (b) is open, and the bag is emptied by the vacuum, thus allowing mixed expired air $\mathrm{P}_{\mathrm{O}_{2}}$ and $\mathrm{P}_{\mathrm{CO} 2}$ to be monitored by the gas analyzer, while the subject inspires. When the bag is completely collapsed, the switch is released: valve (a) opens, valve (b) closes, and the system is ready for the next expiration.

The operation of the electric switch can be synchronized with the expiratory cycle either by direct observation of the bag or by following its volume changes on the recorded profile (Fig. 2). (See Appendix for detailed calculation and procedure.)

\section{Results}

$\mathrm{P}_{\mathrm{O}_{2}}, \mathrm{P}_{\mathrm{CO}_{2}}$ and bag volume changes, are reported in Fig. 2 for a subject during transition between exercise and recovery. The $\mathrm{P}_{\mathrm{O}_{2}}$ tracings between the artifacts, corresponding to the opening and closure of the solenoid valves, are practically horizontal thus indicating a good mixing of expired air. Each segment of the $\mathrm{P}_{\mathrm{O}_{2}}$ and $\mathrm{P}_{\mathrm{CO}_{2}}$ tracings reflects the composition of the immediately preceding $\mathrm{V}_{\mathrm{T}}$. Therefore $\dot{V} \mathrm{O}_{2}$ s.b. can be calculated from tracings of this type and from the pressure and temperature of the expired air. These last were $4-6 \mathrm{~cm}$ of water lower than and $4^{\circ}-8^{\circ} \mathrm{C}$ higher than ambient, respectively, depending on air flow and (for temperature only) room temperature.

\section{Validity of the Method}

After 5 min of exercise, when a steady state was attained, $\dot{V O}_{2}$ s.b. was measured over a number of breaths corresponding to about $1 \mathrm{~min}$, and the overall mean $\dot{V} \mathrm{O}_{2}$ s.b. was calculated. Without interrupting the exercise, the expired air was then collected into a large Tissot spirometer for $30 \mathrm{~s}$, thus allowing steady state $\dot{V} \mathrm{O}_{2}\left(\dot{V} \mathrm{O}_{2 s}\right)$ to be calculated according to the standard open circuit method. The results of a set of determinations at rest and at 4 increasing work intensities (Table 1), indicate that no unidirectional errors affected the calculated $\dot{V} \mathrm{O}_{2 \text { s.b. }}$.

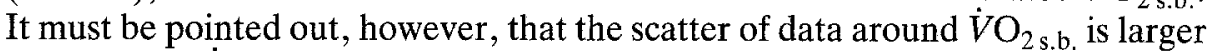
than around $\dot{V} \mathrm{O}_{2 \mathrm{~s}}$, a fact that reflects the large $\mathrm{O}_{2}$ uptake variations from one breath to the other. These large variations may depend on changes of functional

Table 1. $\dot{V} \mathrm{O}_{2}$ ( \pm S.D.) at rest and at four increasing work loads: (1) measured by conventional open circuit methods over periods of $30 \mathrm{~s}$ each $\left(\mathrm{VO}_{2 \mathrm{~s}}\right)$ and (2) calculated as average $\left(\mathrm{VO}_{2 \text { s.b. }}\right)$ of four periods of $1 \mathrm{~min}$ each, on the average number of breaths indicated

\begin{tabular}{lllll}
\hline & $\begin{array}{l}\dot{V O}_{2 \mathrm{~s}} \\
(1 / \mathrm{min})\end{array}$ & $\mathrm{n}$ & $\begin{array}{l}\dot{V} \mathrm{O}_{2 \mathrm{s.b}} \\
(\mathrm{l} / \mathrm{min})\end{array}$ & $\begin{array}{l}\text { Average } \\
\text { No. of breaths } \\
\text { per min }\end{array}$ \\
\hline Rest & $0.32 \pm 0.03$ & 4 & $0.30 \pm 0.08$ & 13 \\
1 & $0.98 \pm 0.04$ & 4 & $1.00 \pm 0.15$ & 17 \\
2 & $2.00 \pm 0.08$ & 4 & $2.10 \pm 0.19$ & 25 \\
3 & $2.99 \pm 0.10$ & 4 & $2.90 \pm 0.20$ & 28 \\
4 & $3.65 \pm 0.11$ & 4 & $3.75 \pm 0.25$ & 32 \\
\hline
\end{tabular}


residual capacity (Wessel et al. 1979) as well as of the ratio of expiration to inspiration time from one breath to the next.

\section{Discussion and Conclusions}

The system can be automated by connecting the electric valves to a pressure sensor. However, the choice of the pressure threshold which triggers the opening (or closing) of the valves is extremely critical: if too high it is subjectively disturbing, if low (and not disturbing) it leads to instability. We therefore deliberately set out for a less elegant, but safer, hand-operated switch.

The use of an electronic system for conversion of $\mathrm{P}_{\mathrm{O}_{2}}$ and $\mathrm{P}_{\mathrm{CO}_{2}}$ to dry gas fractions frees one from the need of continuously recording the expired gas temperature and pressure.

In addition, the calculations required by this method are extremely simple so that with negligible effort the system can be adapted for automatic analysis ("on" or "off" line), with a minimum waste of computer time.

Respiratory rates higher than $40 / \mathrm{min}$ and high ventilations, as during heavy exercise, do not pose serious problems, as the time required to empty the bag is about $0.5 \mathrm{~s}$ (for $V_{\mathrm{T}}=2.5 \mathrm{l}$ ), thus allowing frequencies up to $\simeq 60 / \mathrm{min}$ and ventilations of $\simeq 150 \mathrm{l} / \mathrm{min}$ (ATPS). Furthermore, greater f's and $\dot{V}_{\mathrm{E}}$ 's can presumably be accomodated with adequate manipulations of the geometry of the system (internal diameters and lengths of tubes, etc.).

A further advantage of this system is that the $\mathrm{O}_{2}$ and $\mathrm{CO}_{2}$ analyzers need not be extremely fast, nor need they have the same response time, as the time available for gas analysis is of the order of $0.5 \mathrm{~s}$, or more. Again, no sophisticated spirometers are needed, the only necessary characteristics being a fairly low resistance.

In conclusion, the main improvement of the present method is the reduction of the dead space of the system to a minimum $(70 \mathrm{ml})$, together with the simplicity of the calculation required to determine $\mathrm{VO}_{2}$ of a single breath.

Acknowledgements. The authors would like to thank Mr. Angelo Colombini and Mr. Marco Pellegrini for their skillful technical assistance.

\section{Appendix}

All the variables necessary to calculate $\mathrm{VO}_{2}$ s.b. can be obtained from the tracings of Fig. 2, as follows:

1. $\mathrm{O}_{2}$ and $\mathrm{CO}_{2}$ dry fractions in expired air $(\mathrm{Fx})$ are calculated as: $\mathrm{Fx}=\mathrm{Px} /\left(\mathrm{P}_{\mathrm{T}}-\mathrm{PH}_{2} \mathrm{O}\right)$ where $\mathrm{Px}$ is the gas partial pressure, $P_{T}$ the total gas pressure measured at the sampling level, and $\mathrm{PH}_{2} \mathrm{O}$ the water vapour pressure, assuming saturation of expired air and from air temperature measured the sampling level.

2. From $\mathrm{F}_{\mathrm{EO}_{2}}$ and $\mathrm{F}_{\mathrm{ECO}_{2}}, \mathrm{~F}_{\mathrm{IO}_{2}}^{\prime}$ is calculated as:

$\mathrm{F}_{\mathrm{IO}_{2}}^{\prime}=\frac{1-\left(\mathrm{F}_{\mathrm{EO}_{2}}+\mathrm{F}_{\mathrm{ECO}_{2}}\right)}{0.7904} \cdot 0.2094$

where 0.2094 and 0.7904 are the $\mathrm{O}_{2}$ and $\mathrm{N}_{2}$ fraction of inspired air, respectively. 
3. The pulmonary ventilation of each breath (STPD) is given by $V_{T} / t$ (Fig. 2), where $t$ is the time of a breathing cycle and can be easily assessed from the distance between two consecutive inspiratory phases. STPD (or BTPS) conversion factors are calculated from ambient pressure and box temperature, respectively.

4. $\dot{V} \mathrm{O}_{2}$ s.b. can now be calculated, with the aid of Eq. (1).

\section{References}

Beaver WL, Wasserman K, Whipp BJ (1973) On line computer analysis and breath-by-breath graphical display of exercise functions tests. J Appl Physiol 32:128-132

Casaburi R, Whipp BJ, Wasserman K, Beaver WL, Koyal SN (1977) Ventilatory and gas exchange dynamics in response to sinusoidal work. J Appl Physiol 42:300-311

Casaburi R, Whipp BJ, Wasserman K, Koyal SN (1978) Ventilatory and gas exchange responses to cycling with sinusoidally varying pedal rate. J Appl Physiol 44:97-103

Cerretelli P, Sikand R, Farhi LE (1966) Readjustments in cardiac output and gas exchange during onset of exercise and recovery. J Appl Physiol 21:1345-1350

Cerretelli P, Shindell D, Pendergast DR, di Prampero PE, Rennie DW (1977) Oxygen uptake transients at the onset and offset of arm and leg work. Respir Physiol 30:81-97

Cerretelli P, Pendergast D, Paganelli WC, Rennie DW (1979) Effects of specific muscle training on $\mathrm{VO}_{2}$ on-response and early blood lactate. J Appl Physiol 47:261-269

Diamond LB, Casaburi R, Wasserman K, Whipp BJ (1977) Kinetics of gas exchange and ventilation in transitions from rest or prior exercise. J Appl Physiol 43: 704-708

di Prampero PE, Davies CTM, Cerretelli P, Margaria R (1970) An analysis of $\mathrm{O}_{2}$ debt contracted in submaximal exercise. J Appl Physiol 29:547-551

di Prampero PE, Peeters L, Margaria R (1973) Alactic $\mathrm{O}_{2}$ debt and lactic acid production after exhausting exercise in man. J Appl Physiol 34:628-632

Hagberg JM, Nagle FJ, Carlson JL (1978) Transient $\mathrm{O}_{2}$ uptake response at the onset of exercise. J Appl Physiol 44: 90-92

Henry FM (1951) Aerobic oxygen consumption and alactic debt in muscular work. J Appl Physiol 3: $227-238$

Linnarson D (1974) Dynamics of pulmonary gas exchange and heart rate changes at start and end of exercise. Acta Physiol Scand [Suppl] 215:1-68

Margaria R, Mangili F, Cuttica F, Cerretelli P (1965) The kinetics of oxygen consumption at the onset of muscular exercise in man. Ergonomics 8:29-52

Morabito A, Gussoni M, Veicsteinas A, Cerretelli P (1976) Acquisizione ed elaborazione di parametri respiratori mediante accoppiamento die strumenti di analisi con un calcolatore elettronico. Spring Meeting of the Ital Physiol Soc

Pearce DH, Wilhorn HT Jr, (1977a) Dynamic and steady state respiratory responses to bicycle exercise. J Appl Physiol 42:959-967

Pearce DH, Willhorn HT Jr, Holloman GH Jr, Reynolds WJ (1977b) Computer-based system for analysis of respiratory responses to exercise. J Appl Physiol 42: 968-975

Wessel HV, Stout RL, Bastanier CK, Paul MH (1979) Breath-by-breath variation of FRC: effect of $\dot{V} \mathrm{O}_{2}$ and $\dot{V} \mathrm{CO}_{2}$ measured at the mouth. J Appl Physiol 46:1122-1126

Whipp BJ (1971) Rate constant for the kinetics of oxygen uptake during light exercise. J Appl Physiol 30:261-263

Whipp BJ, Wasserman K (1972) Oxygen uptake kinetics for various intensities of constant-load work. J Appl Physiol 33:351-356 